\title{
Jejuno-jejunal Intussusception as an Unusual Cause of Acute Abdomen of a 26 Year Female - A Case Report
}

\author{
Rahman MM1, Ahmad S², Singha $\mathrm{JL}^{3}$, Alam SI ${ }^{4}$, Islam $\mathrm{M}^{5}$, Hasan $\mathrm{MR}^{6}$, Sutana $\mathrm{S}^{7}$
}

Conflict of Interest: None Received: $06-05-2018$

Accepted: $16-10-2018$

www.banglajol.info/index.php/JSSMC

Key Words: Intussusception, Jejunum, inflammatory fibroid polyp

\begin{abstract}
:
Intussusception is a relatively common etiology of abdominal pain in pediatric population. In adults, on the other hand, this entity is seen infrequently and a lead point can be recognized in a vast majority of cases. A 27 year old woman who was admitted in the Surgery Department of Shaheed Sohrawardy Medical College Hospital after experiencing severe upper abdominal pain associated with nausea, vomiting and fever. Later on the patient developed features of intestinal obstruction. Ultrasonography demonstrated small bowel intussusception. A jejunal intussusception $50 \mathrm{~cm}$ distal to the dudeno-jejunal junction was found during laparotomy. Resection and anasto mosis was performed as gut was not viable. A diagnosis of jejunal inflammatory fibroid polyp was made based on the histological findings which act as a lead point for jejunal intussusception.
\end{abstract}

[J Shaheed Suhrawardy Med Coll 2018; 10(2): 111-114] DOI: https://doi.org/10.3329/jssmc.v10i2.41171

\section{Introduction:}

Intussusception is the telescopic projection of proximal portion of bowel (called as intussusceptum) into an adjacent distal bowel (called as intussuscipiens). ${ }^{1}$ It is an infrequent cause of abdominal pain in adults. The lead point of intussusception is usually in the small intestine (enteroenteric) ranging from about $77-88 \%$, in colon (colocolic) in 6-15\% and ileocecal in about 5-7\% and gasteroenteric in about $2 \%$ of the cases. ${ }^{2}$ The precise mechanism of intestinal intussusception remains unclear. However, it is believed that any lesion in the bowel wall or

1. Professor Dr. Md. Mustafizur Rahman, Professor, Department of Surgery, Shaheed Suhrawardy Medical College \& Hospital, Dhaka

2. Dr. Sami Ahmad, Associate Professor, Department of Surgery, Shaheed Suhrawardy Medical College \& Hospital, Dhaka

3. Dr. Jawhar Lal Singha, Associate Professor, Department of Surgery, Shaheed Suhrawardy Medical College \& Hospital, Dhaka

4. Dr. Shoaeb Imtiaz Alam, Honorary Medical Officer, Department of Surgery, Shaheed Suhrawardy Medical College \& Hospital, Dhaka

5. Dr. Mansurul Islam, Assistant Registrar, Department of Surgery, Shaheed Suhrawardy Medical College \& Hospital, Dhaka

6. Dr. Muhammad Rashedul Hasan, Medical Officer, Department of Surgery, Shaheed Suhrawardy Medical College \& Hospital, Dhaka

7. Dr. Salsabil Sutana, Honorary Medical Officer, Department of Surgery, Shaheed Suhrawardy Medical College \& Hospital, Dhaka

Correspondence to: Professor Dr. Md. Mustafizur Rahman, Professor, Department of Surgery, Shaheed Suhrawardy Medical College \& Hospital, Dhaka irritant within the lumen that alters normal peristaltic activity, forming leading edges for the intussusceptum, may initiate invagination. Ingested food and subsequent peristaltic activity of the bowel produces an area of constriction above the stimulus and relaxation below, thus telescoping the lead point through the distal bowel lumen. ${ }^{3,4}$ As opposed to that in children, most of the cases (about 90\%) in adults have an identifiable cause while the rest are idiopathic. ${ }^{5}$ Most lead points in the gastrointestinal tract involve primary or metastatic malignancy, lipomas, leiomyomas, adenomas, neurofibromas, postoperative adhesions, Meckel's diverticulum, foreign bodies, vascular anomalies, lymphoid hyperplasia, trauma, celiac disease, cytomegalovirus colitis, lymphoid hyperplasia secondary to lupus, HenochSchönlein purpura, appendicular stump, or inflammatory fibroid polyps. ${ }^{5}$

In a study of 58 cases of surgically proven adult intussusceptions, most patients were found to have presented with signs and symptoms suggestive of bowel obstruction. ${ }^{6}$ However it may present in a variety of spectrum ranging from acute to chronic symptoms such as nausea,vomiting, malena, constipation, weight loss, fever, diarrhea, abdominal mass and rarely abdominal pain. ${ }^{6}$ Here we present a case of a young female with jejunojejunal intussusception presented to us with abdominal pain caused by inflammatory fibroid polyps. 


\section{Case report:}

A 27 years old married female was admitted to our department with sudden severe colicky pain in the epigastric region for one day which radiated to back, aggravated on taking food and lying flat, relieved to some extent on sitting and leaning forward associated with fever, nausea and vomiting. Her physical examination revealed normal vital parameters. On abdominal examination, there was tenderness in epigastric region. But her abdomen was soft and there was no lump or organomegaly. Bowel sound was present. Digital rectal examination demonstrated normal findings. Other examinations also showed normal findings. With this clinical findings our impression was that it was a case of acute pancreatitis and we started to manage the patient accordingly. Surprisingly, the next day her abdomen became distended and tender. That time Bowel sound was also absent. Her Investigation report showed neutrophilic leukocytosis with elevated ESR with

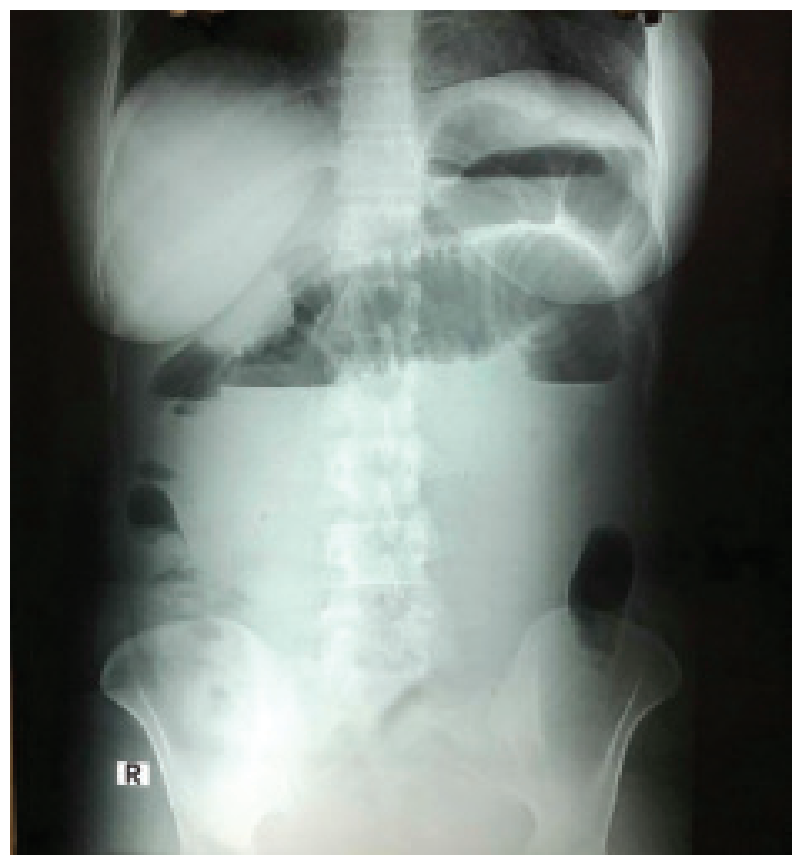

Fig-1: Plain x-ray of abdomen showing features of small bowel obstruction.

normal serum amylase, lipase level. Serum electrolytes, liver function and renal function test results were within normal limits. Her abdominal X- Ray demonstrated multiple centrally present air fluid level indicating small bowel obstruction. (Fig-1) Abdominal ultra-sonogram showed a fairly mixed echogenic area predominantly hypoechoic area having concentric layer pattern in left lumber region suggestive of small bowel intussusception. (Fig-2) The clinical symptoms and ultrasonographic images were consistent with intestinal obstruction caused by intussusception. Thus, laparotomy with midline incision was performed. On exploration, a jejunojejunal intussusception was found $50 \mathrm{~cm}$ distal to dudeno-jejunal

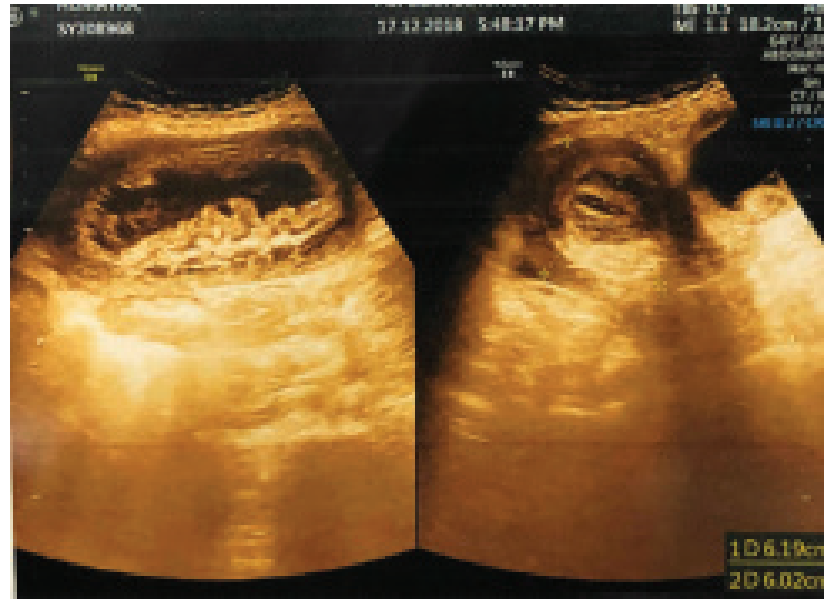

Fig-2: Ultrasonogram showing intussusception of small bowel.

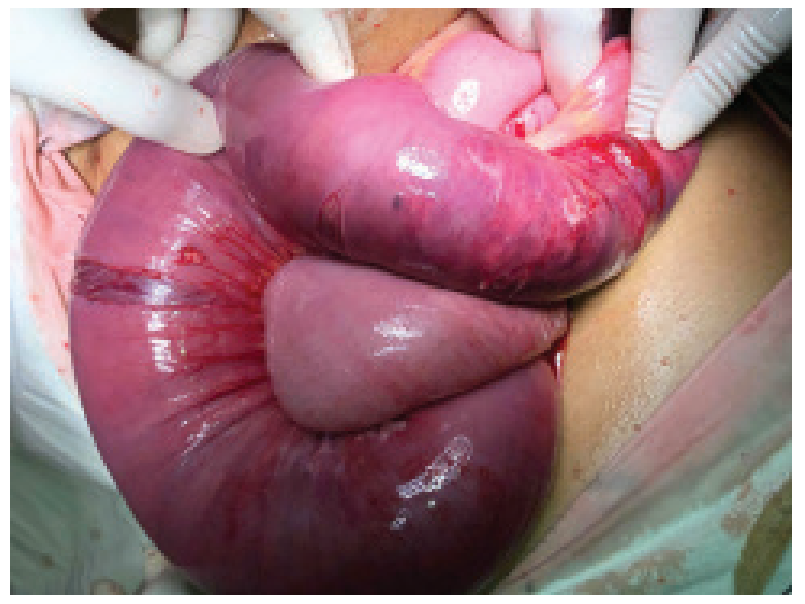

Fig-3 : Peroperative view of jejunal Intussusception

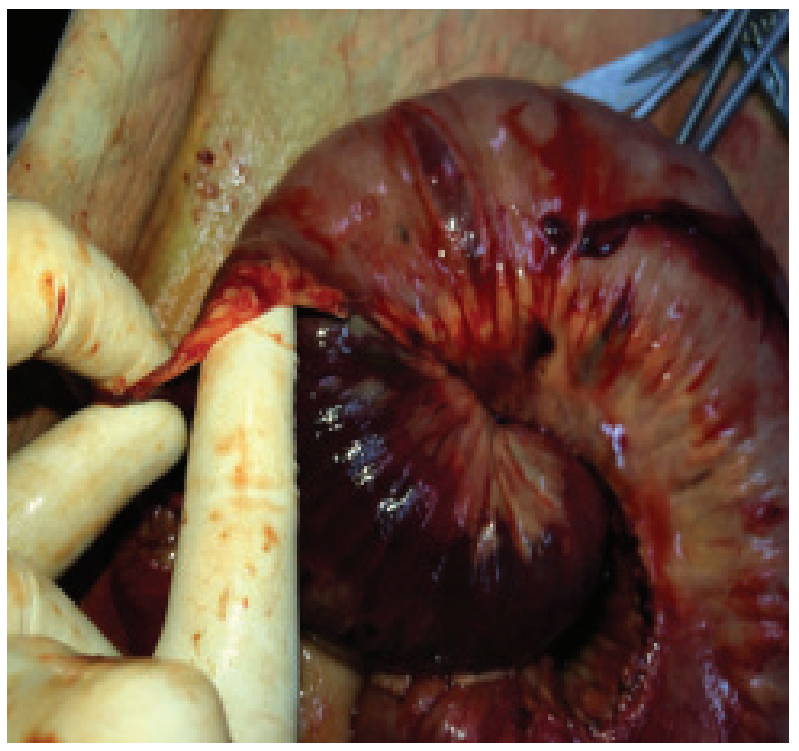

Fig-4: Peroperative view showing gangrenous small bowel 


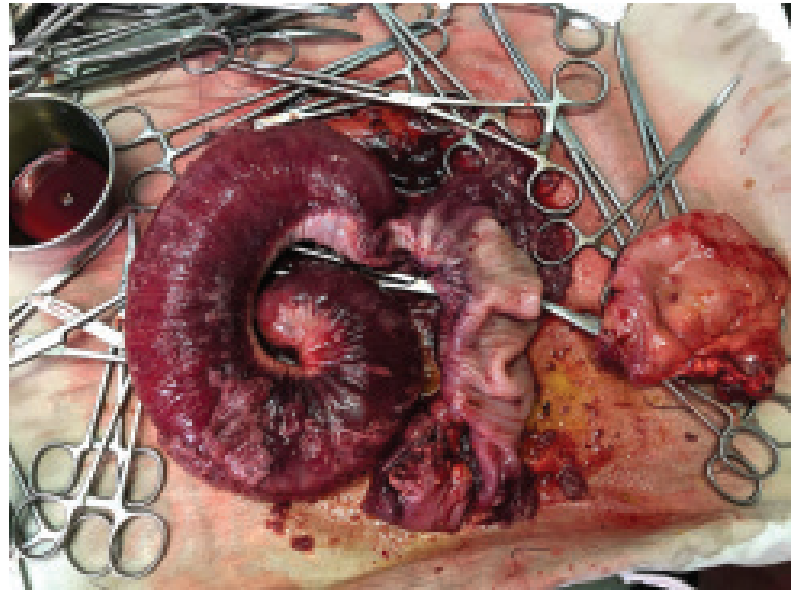

Fig-5 : Peroperative view of gangrenous small gut

(D-J) junction. The intussuscepted intestinal segments were gangrenous. (Fig-3,4,5) So segmental resection of the intussuscepted jejunum was performed followed by end to end anastomosis. Macroscopically, the resected segment of the jejunum was $40 \mathrm{~cm}$ in length. (Fig-4) Histopathological examination showed an inflammatory fibroid polyp measuring $7.5 \mathrm{~cm} \times 4.5 \mathrm{~cm}$, composed of an edematous stroma containing plasma cells, lymphoid nodules and eosinophils which acted as a lead point for intussusception. Her post-operative period was uneventful and she was discharged with advice on $7^{\text {th }}$ postoperative day.

\section{Discussion:}

Acute abdominal pain is a common and challenging complaint in the surgery department. Intussusception in adults, although rare, is an important etiology to consider. The classic pediatric presentation of acute intussusception (a triad of cramping abdominal pain, 'red currant jelly' and a palpable tender mass) is rare in adults. ${ }^{7}$ The clinical presentation of intussusception in adults can be nonspecific varying from nausea, vomiting, gastrointestinal bleeding, alteration of bowel habits, constipation, abdominal distension and very rarely acute abdominal pain leading to delays in diagnosis. ${ }^{7}$ In contrast to intussusceptions in children, which are typically primary or idiopathic, most adult intussusceptions are caused by a structural lesion. A significant proportion of these lead points are malignant neoplasms, accounting for $66 \%$ of colonic intussusceptions and $30 \%$ of cases in the small intestine. ${ }^{8}$ That's why intussusception is an important differential diagnosis to consider for acute abdominal pain.

In this case, the patient presented with symptoms mimicking acute pancreatitis but subsequently developed features of intestinal obstruction which created a diagnostic dilemma. Later on the diagnosis of intussusception was made by ultra-sonogram. Similar type of a cases were reported by Mehta et al. which were managed surgically. ${ }^{9}$

Due to non-specific presentation, the diagnosis of adult intussusception is very difficult. An accurate diagnosis is based on a good medical history, thorough physical examination, and specific imaging modalities, such as Xray, ultrasonography, computed tomography (CT), magnetic resonance imaging (MRI), endoscopic procedures, angiography, and capsule endoscopy. Though abdominal CT is currently considered the most sensitive radiological method for confirming intussusception with a reported diagnostic accuracy of 58\%-100\%, ultrasonogram can also be considered a useful tool in the diagnosis of intussusception in both pediatric and adult cases. ${ }^{10}$ Its classical imaging features include the target or doughnut sign in the transverse view. ${ }^{10}$ In the present case the diagnosis was made by ultrasonogram which helped to manage the patient quickly and efficiently.

Inflammatory fibroid polyps have been reported as a rare cause of adult intussusception. ${ }^{11}$ Macroscopically, these tumors are pedunculated or sessile arise from the submucosa, and project into the bowel lumen. ${ }^{11}$ The mucosal surface is usually ulcerated and pale. Microscopically, it is composed of mononuclear, spindleshaped cells, forming a whirl-like structure. ${ }^{11}$ Due it's peduncle it may act as a lead point for intussusception which happened in the current case.

The optimal management of adult intussusception remains controversial. Most of the debate focuses on the issue of primary en bloc resection versus initial reduction, followed by a more limited resection. ${ }^{12}$ The reduction of an intussusception secondary to a malignant lead point is potentially detrimental, as there is the theoretic risk of intraluminal seeding and venous embolization in regions of ulcerated mucosa. ${ }^{13}$ Furthermore, the inability to differentiate malignant from benign etiology preoperatively or intraoperatively also dictates that small bowel intussusception be resected without reduction. ${ }^{13}$ In this case though per operatively there was no features of malignancy the primary resection of small intestine followed by end to end anastomosis was done as the gut was not viable.

\section{Conclusion:}

Adult intussusception is an unusual and challenging condition for the surgeons. Treatment usually requires resection of the involved bowel segment. Reduction can be attempted in small-bowel intussusception if the segment involved is viable or malignancy is not suspected; however, a more careful approach is recommended in colonic intussusception because of a significantly higher coexistence of malignancy. 


\section{Reference:}

1. Erkan N, Haciyanli M, Yildirim M, Sayhan H, Vardar E, Polat AF. Intussusception in adults: an unusual and challenging condition for surgeons. Int J Colorectal Dis. 2005;20(5): 452-456.

2. Rea JD, Lockhart ME, Yarbrough DE, Leeth RR, Bledsoe SE, Clements RH. Approach to management of intussusception in adults: a new paradigm in the computed tomography era. Am Surg. 2007;73(11):1098-105.

3. Wang N, Cui XY, Liu Y, Long J, Xu YH, Guo RX, Guo KJ. Adult intussusception: a retrospective review of 41 cases. World J Gastroenterol. 2009;15:3303-3308.

4. Yakan S, Caliskan C, Makay O, Denecli AG, Korkut MA. Intussusception in adults: clinical characteristics, diagnosis and operative strategies. World J Gastroenterol. 2009;15:1985-1989.

5. Marinis A, Yiallourou A, Samanides L, Dafnios N, Anastasopoulos G, Vassiliou I, Theodosopoulos T. Intussusception of the bowel in adults: a review. World $\mathrm{J}$ Gastroenterol. 2009;15:407-411.

6. Azar T, Berger DL. Adult intussusceptions. Ann Surg. 1997;226(2):134-138.

7. Takeuchi K, Tsuzuki Y, Ando T, Sekihara M, Hara T, Kori T, Kuwano $H$. The diagnosis and treatment of adult intussusception. J Clin Gastroenterol. 2003;36(1):18-21.
8. Martín-Lorenzo JG, Torralba-Martinez A, Lirón-Ruiz R, Flores-Pastor B, Miguel-Perelló J, Aguilar-Jimenez J, et al. Intestinal invagination in adults: preoperative diagnosis and management. Int J Colorectal Dis. 2004 Jan;19(1):68-72

9. Mehta S, Mucci T, Long W, Witkiewicz A, Mastrangelo MJ, Rosato EL, Berger AC. Jejunal Intussusception as an Unusual Cause of Abdominal Pain in an Adult Mcgill J Med. 2009 Jan; 12(1): 28-30.

10. Sampson MA, Lyons TJ, Nottingham J, Naik D. Ultrasound diagnosis of recurrent intussusception due to inflammatory fibroid polyp of the ileum. J Ultrasound Med. 1990;9:423425 .

11. Singhal $\mathrm{M}$, Singh $\mathrm{P}$, Misra V, Dhingra V, Bhatia R. Inflammatory fýbroýd polyp of small ýntestýne: Report of two cases wýth revýew of lýterature. JCDR. 2010;4:32413244 .

12. Barussaud M, Regenet N, Briennon X, de Kerviler B, Pessaux P, Kohneh-Sharhi N, Lehur PA, Hamy A, Leborgne J, le Neel JC, et al. Clinical spectrum and surgical approach of adult intussusceptions: a multicentric study. Int J Colorectal Dis. 2006;21:834-839

13. Yalamarthi S, Smith RC. Adult intussusception: case reports and review of literature. Postgrad Med J. 2005;81:174-177 